\title{
Acid ceramidase is a novel drug target for pediatric brain tumors
}

\author{
Ninh B. Doan 1,2 , Ha S. Nguyen², Andrew Montoure ${ }^{2}$, Mona M. Al-Gizawiy ${ }^{3}$, Wade \\ M. Mueller ${ }^{2}$, Shekar Kurpad ${ }^{2}$, Scott D. Rand ${ }^{3}$, Jennifer M. Connelly ${ }^{4}$, Christopher R. \\ Chitambar ${ }^{4}$, Kathleen M. Schmainda, ${ }^{3,6}$, Shama P. Mirza ${ }^{1,7,8}$ \\ ${ }^{1}$ Biotechnology and Bioengineering Center, Medical College of Wisconsin, Milwaukee, Wisconsin, 53226, USA \\ ${ }^{2}$ Department of Neurosurgery, Medical College of Wisconsin, Milwaukee, Wisconsin, 53226, USA \\ ${ }^{3}$ Department of Radiology, Medical College of Wisconsin, Milwaukee, Wisconsin, 53226, USA \\ ${ }^{4}$ Department of Neurology, Medical College of Wisconsin, Milwaukee, Wisconsin, 53226, USA \\ ${ }^{5}$ Department of Medicine, Hematology/Oncology, Medical College of Wisconsin, Milwaukee, Wisconsin, 53226, USA \\ ${ }^{6}$ Department of Biophysics, Medical College of Wisconsin, Milwaukee, Wisconsin, 53226, USA \\ ${ }^{7}$ Obstetrics and Gynecology, Medical College of Wisconsin, Milwaukee, Wisconsin, 53226, USA \\ ${ }^{8}$ Department of Chemistry and Biochemistry, University of Wisconsin, Milwaukee, Wisconsin, 53211, USA \\ Correspondence to: Ninh B. Doan, email: ndoan@mcw.edu
}

Keywords: pediatric glioblastoma, acid ceramidase inhibitors, carmofur, glioblastoma, medulloblastoma

Received: September 12, $2016 \quad$ Accepted: February 15, 2017 Published: March 01, 2017

Copyright: Doan et al. This is an open-access article distributed under the terms of the Creative Commons Attribution License (CC-BY), which permits unrestricted use, distribution, and reproduction in any medium, provided the original author and source are credited.

\section{ABSTRACT}

Pediatric brain tumors are the most common solid tumors in children and are also a leading culprit of cancer-related fatalities in children. Pediatric brain tumors remain hard to treat. In this study, we demonstrated that medulloblastoma, pediatric glioblastoma, and atypical teratoid rhabdoid tumors express significant levels of acid ceramidase, where levels are highest in the radioresistant tumors, suggesting that acid ceramidase may confer radioresistance. More importantly, we also showed that acid ceramidase inhibitors are highly effective at targeting these pediatric brain tumors with low IC $_{50}$ values $(4.6-50 \mu \mathrm{M})$. This data suggests acid ceramidase as a novel drug target for adjuvant pediatric brain tumor therapies. Of these acid ceramidase inhibitors, carmofur has seen clinical use in Japan since 1981 for colorectal cancers and is a promising drug to undergo further animal studies and subsequently a clinical trial as a treatment for pediatric patients with brain tumors.

\section{INTRODUCTION}

Malignant brain tumors are the most frequent solid tumors in the pediatric population; they constitute $20 \%$ to $30 \%$ of all pediatric cancers and represent the predominant cause of cancer-related deaths in childhood [1]. In this study, we focus on three malignant brain tumors - atypical rhabdoid/teratoid tumor (ATRT), glioblastoma, and medulloblastoma. In particular, ATRT is associated with a miserable prognosis, with medial survival at 9 to 17 months [2]. No guidelines exist for optimal treatment and different multimodal protocols are presently being studied to improve outcomes [2]. For pediatric glioblastoma, most institutions employ surgery and adjuvant radiotherapy, but the role of chemotherapy remains investigational [3, 4]. Median overall survival ranges from 15 months up to 40 months in various small series [4]. Of the three, medulloblastoma has been the most studied with the best overall survival. The standard treatment is chemotherapy (adjuvant lomustine, vincristine, cyclophosphamide, and cisplatin) after reduceddose radiotherapy concomitantly with vincristine [1, 5-7]. Reported 5-year event-free survival is $80 \%[6,7]$. However, given the longer life expectancy, a key concern is the development of long-term toxicity associated with current treatment protocols $[6,8,9]$.

A potential new chemotherapeutic target for these tumors is acid ceramidase. The enzyme helps regulate activity of ceramides in cells, affecting survival, growth, and death of tumor cells [10]. High levels of this enzyme have been discovered in various types of human cancer [10]. Moreover, over-expression of the enzyme in tumor cells confers resistance to apoptosis, while inhibition augments response to chemotherapeutic agents and radiation [10]. In this study, we showed 
that acid ceramidase inhibitors are highly effective at targeting medulloblastoma, pediatric glioblastoma, and atypical teratoid rhabdoid tumors. The data suggest acid ceramidase is a novel drug target for pediatric brain tumors. We also demonstrated that an acid ceramidase inhibitor called carmofur, which has seen clinical use in Japan since 1981 for colorectal cancers, is a promising drug to undergo further animal studies and subsequently a clinical trial for pediatric patients with brain tumors.

\section{RESULTS}

\section{Patient derived pediatric brain tumor cells express significant levels of ASAH1}

ASAH1 has been shown to correlate with prostate tumor progression, and poor outcomes $[11,12]$. To better understand the role of ASAH1 in pediatric brain tumors, the expression level of ASAH1 in these pediatric tumor cell lines were analyzed. Western blot analysis of CHLA259, CHLA266, SJGBM2, and CHLA200 cells demonstrated significant expression levels of ASAH1 (Figure 1). Of the four, the CHLA200 line, which was generated from a recurrent tumor at autopsy believed to be resisted to both chemo- and radiotherapy $[13,14]$, was noted to have the highest expression level of ASAH1, many fold higher (Figure 1). The SJGBM2 line, which was also generated at autopsy and had progressed despite the previous treatment with chemotherapy, contained the lowest level of ASAH1 among cell lines being studied (Figure 1). Of the four, only the CHLA200 line had prior radiation $[14,15]$. CHLA259 and CHLA266 lines were generated at the time of diagnosis, prior to any therapies [14].

\section{Pediatric brain tumor cells are highly sensitive to ASAH1 inhibitors: $\mathrm{OE}$ and carmofur}

To examine the role of ASAH1 in survival of pediatric brain tumor cells, we used previously identified ASAH1 inhibitors N-oleoylethanolamine (OE) and carmofur $[10,16,17]$. To study their efficacy, MTT assays were performed with OE and carmofur against CHLA259, CHLA266, SJGBM2, and CHLA200 cells [10, 16]. Despite their known multidrug resistance phenotype, all four cell lines were highly sensitive to $\mathrm{OE}$ and carmofur with $\mathrm{IC}_{50}$ values ranging from 4.6, $50 \mu \mathrm{M}$ (Figure 2 and Table 1).

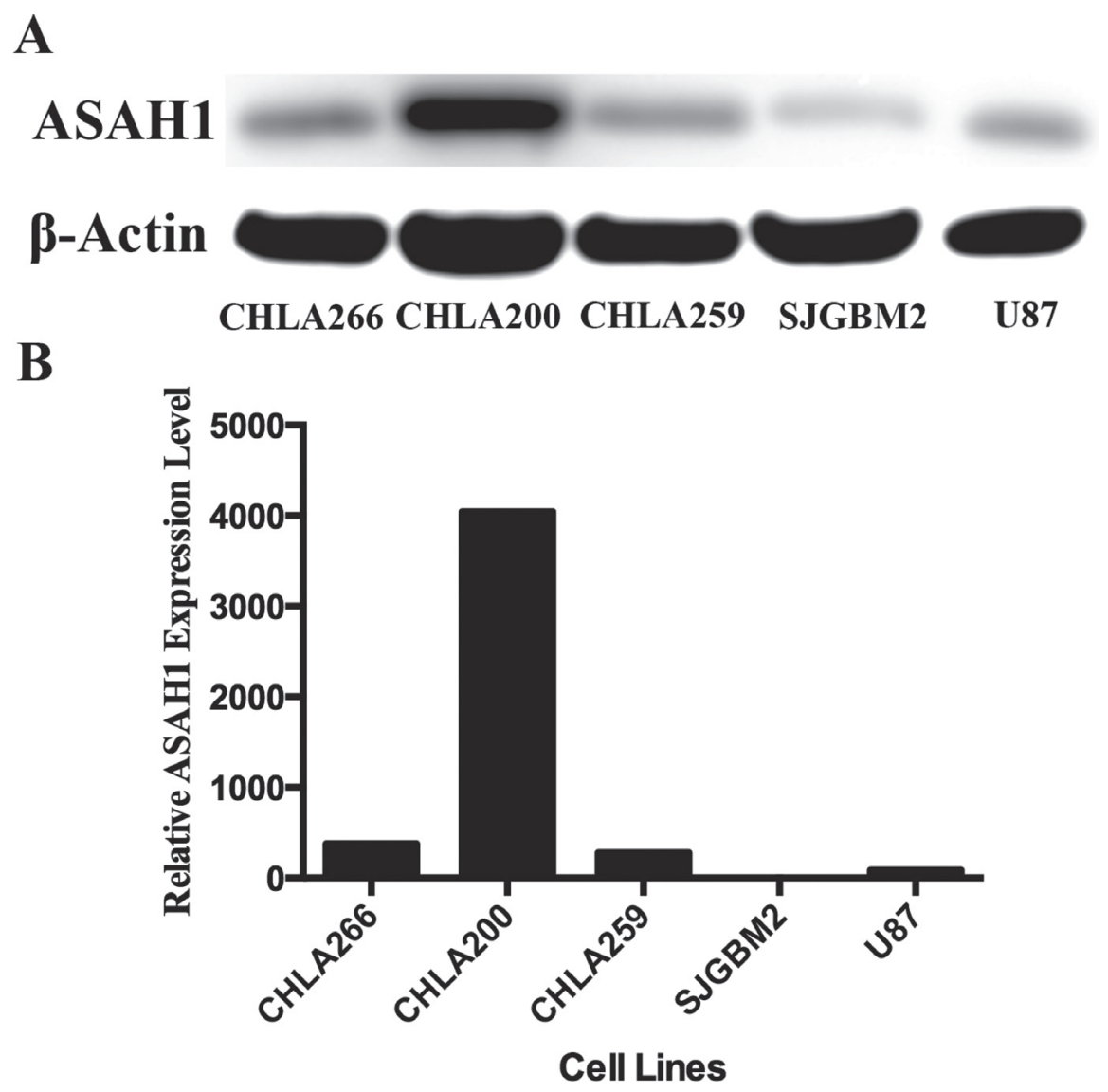

Figure 1: Patient derived pediatric brain tumor cells express high levels of ASAH1. (A) Western blot of 4 patient derived pediatric brain tumors and 1 adult glioblastoma cell line (U87) are shown. The blot was overexposed to show the faint ASAH1 band from SJGBM2 cells. (B) Quantitation of the relative ASAH1 expression level was performed with ImageJ. CHLA200 cells express many folds higher level of ASAH1 than other tumors. 
Table 1: $\mathrm{IC}_{50}$ values range $4.5-50 \mu \mathrm{M}$

\begin{tabular}{|l|c|c|}
\hline \multicolumn{1}{c|}{ Cell Lines } & Carmofur IC & N-oleoylethanolamine IC50 \\
\hline SJGBM2 & $50 \mu \mathrm{M} \pm 1 \mu \mathrm{M}$ & $22 \mu \mathrm{M} \pm 2 \mu \mathrm{M}$ \\
\hline CHLA259 & $26 \mu \mathrm{M} \pm 2 \mu \mathrm{M}$ & $5.6 \mu \mathrm{M} \pm 1 \mu \mathrm{M}$ \\
\hline CHLA200 & $13 \mu \mathrm{M} \pm 3 \mu \mathrm{M}$ & $4.5 \mu \mathrm{M} \pm 1 \mu \mathrm{M}$ \\
\hline CHLA266 & $15 \mu \mathrm{M} \pm 1 \mu \mathrm{M}$ & $41 \mu \mathrm{M} \pm 2 \mu \mathrm{M}$ \\
\hline
\end{tabular}

Carmofur and $\mathrm{OE} \mathrm{IC}_{50}$ values from 4 different pediatric brain tumor cell lines are shown.

CHLA200 cells with the highest expression level of ASAH1 exhibited the most sensitivity to both $\mathrm{OE}$ and carmofur having $\mathrm{IC}_{50}$ values of 5.6 and $26 \mu \mathrm{M}$ for $\mathrm{OE}$ and carmofur, respectively (Table 1).

\section{Pediatric brain tumor cells treated with} carmofur underwent apoptosis as demonstrated by Annexin-V-Alexa-488 conjugate staining

It has been well demonstrated that inhibition of acid ceramidase will elevate the ceramide level, which in turn induces cell apoptosis [16, 18-20]. To test this theory, tumor cells treated with carmofur were exposed to the Annexin-V-Alexa-488 conjugate to evaluate for the evidence of apoptosis. As expected, CHLA259, CHLA266, SJGBM2, and CHLA200 cells treated with carmofur underwent significant stainings with the Annexin-V-Alexa-488 conjugate as demonstrated by fluorescent signals, which strongly suggested these cells underwent apoptosis (Figure 3). Cells that were not exposed to carmofur demonstrated no significant fluorescent signals. Compared to control, cells treated with carmofur became more rounded, changing their shapes, and appeared to be in various stages in disintegration.

\section{Pediatric brain tumors were more sensitive to carmofur than temozolomide}

TMZ is the only chemotherapy drug that has been approved for adult glioblastoma [21]. To compare the effectiveness of carmofur and TMZ at killing tumor cells, we performed MTT cell survival studies with
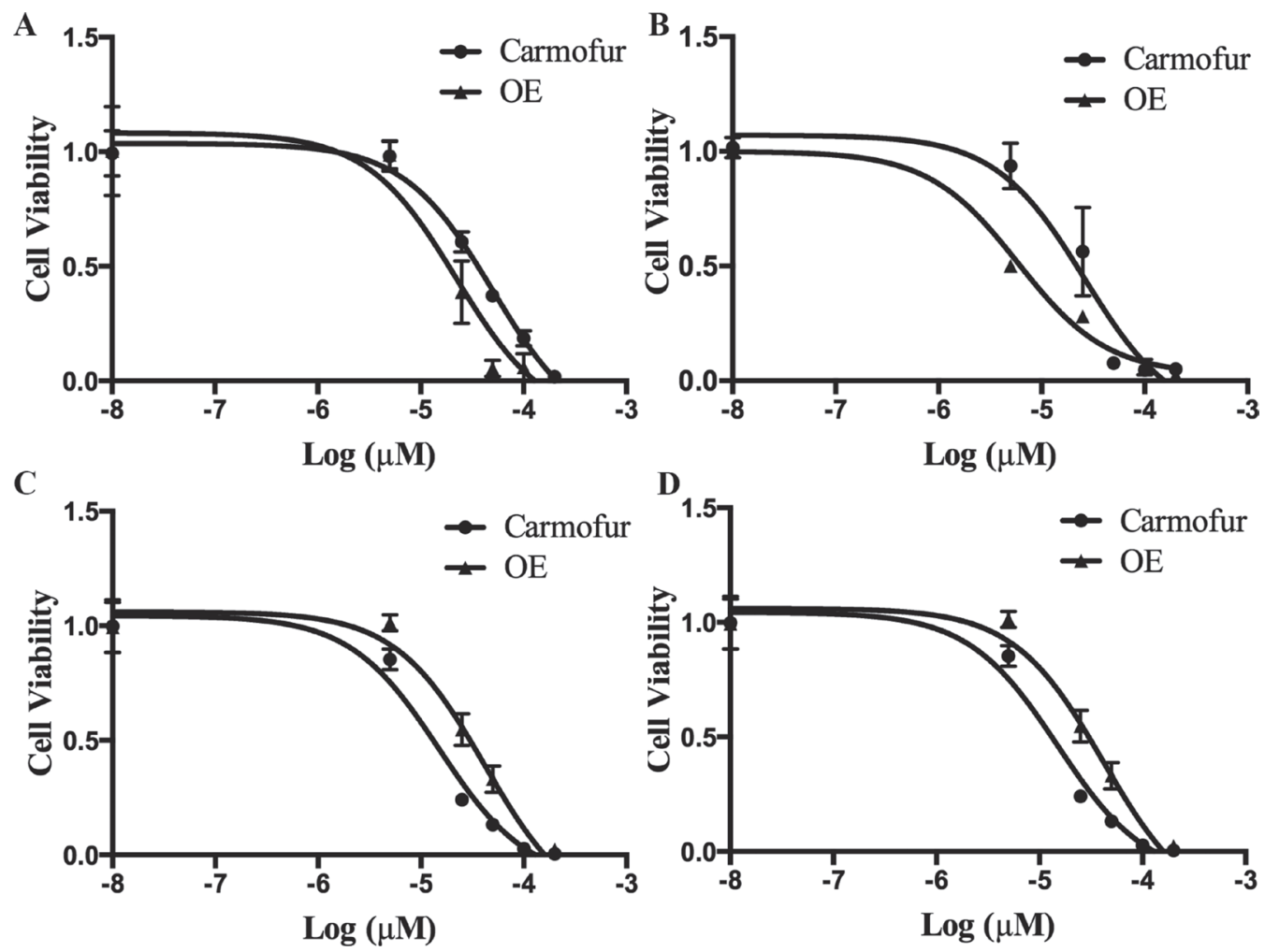

Figure 2: Pediatric brain tumor cells are highly sensitive to ASAH1 inhibitors: OE and carmofur. MTT assays of SJGBM2 (A), CHLA259 (B), CHLA200 (C), and CHLA266 (D) were performed with carmofur and OE. Results are expressed as means and \pm s.e.m $(N=3)$. 
these drugs. MTT assays demonstrated that minimal cell death occurred in CHLA259, CHLA266, SJGBM2, and CHLA200 cells treated with TMZ, while at just half the concentration of $\mathrm{TMZ}$, carmofur treatment resulted in $>50 \%$ cell death (Figure 4 ). Moreover, TMZ actually enhanced the cell growth of CHLA266 and CHLA200 by almost 2-folds compared to the control (Figure 4).

\section{A high level of ASAH1 is associated with a lower level of its substrates and a higher level of its endproducts, ceramides and sphingosines, respectively}

To determine whether a higher level of ASAH1 can modulate the sphingolipid pathway, sphingolipid levels were determined in cells with high (CHLA266) and low (SJGBM2) levels of ASAH1 (Figure 1). As expected, ceramide, the substrate of ASAH1, levels were found to be decreased in CHLA266 cells compared to SJGBM2 cells (Figure 5). In consistent with this pathway, the endproduct of ASAH1, which is sphingosine ( $\mathrm{Sph}$ ), is higher in CHLA266 cells than from SJGBM2 cells. While dihydrosphingosine (dhSph), and sphingosine (Sph) levels were increased in CHLA266 cells, the sphingosine-1- phosphate (Sph-1P) level remained unchanged between CHLA266 and SJGBM2 cells (Figure 5).

\section{Treatment of SJGBM2 cells with carmofur resulted in intracellular accumulation of ceramides}

In an effort to elucidate the mechanism of action, we decided to evaluate the change in intracellular level of ceramides following carmofur treatment. Treating cultures of SJGMB2 cells with $50 \mu \mathrm{M}$ carmofur resulted in intracellular accumulation of various ceramide species, which were identified and quantified by liquid chromatography and mass spectrometry (Figure 6). This finding, which is in consistent with other study [10], suggests that carmofur inhibits ASAH1 activity and elevates tissue ceramide levels.

\section{DISCUSSION}

ASAH1, a lysosome cysteine amidase, plays an important role in the metabolism of sphingolipids by converting ceramide into sphingosine and free fatty acid $[18,22,23]$ (Figure 7). Sphingosine is phosphorylated into
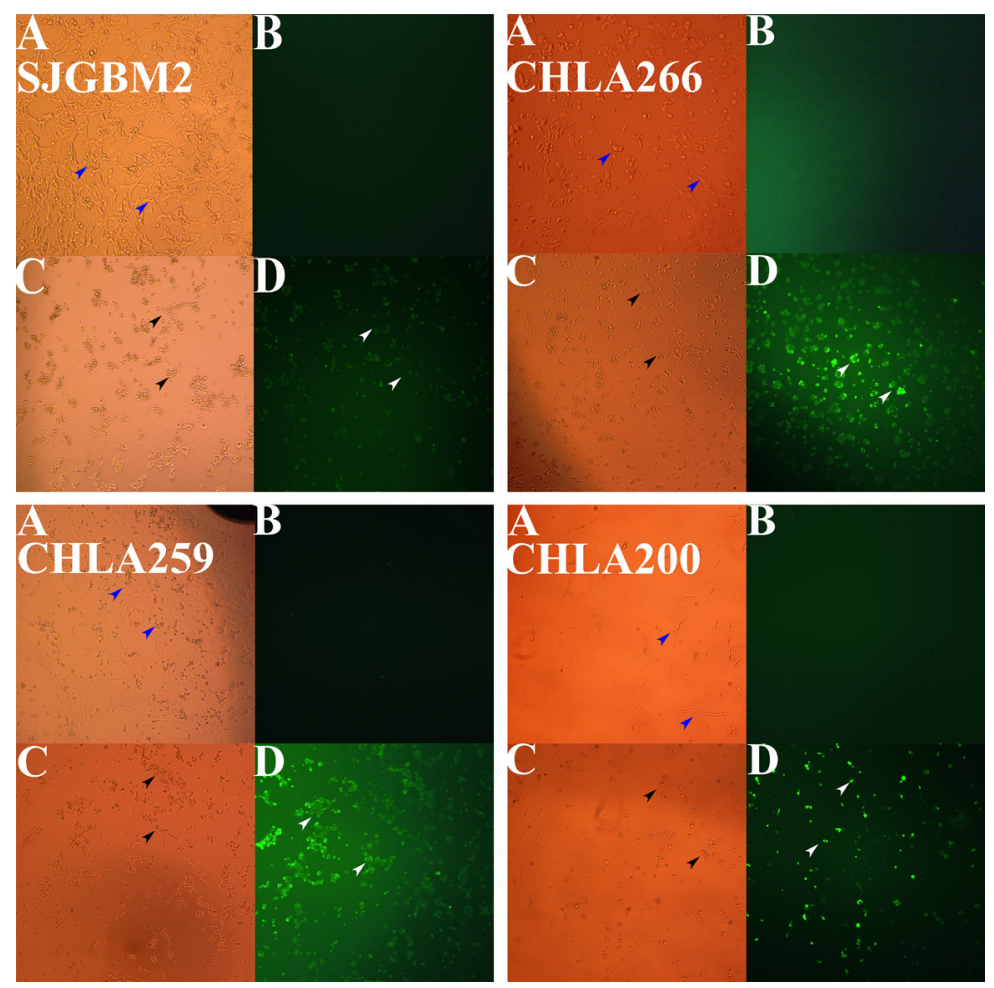

Figure 3: Pediatric brain tumor cells treated with carmofur underwent apoptosis as demonstrated by the AnnexinV-Alexa-488 conjugate staining. Microscopy studies pediatric brain tumors are shown. Top left panel, SJGBM2; top right panel, CHLA266; bottom left panel, CHLA259; bottom right panel, CHLA200; control cells imaged with the brightlight (A), with the fluorescent light (B) vs cells treated (12 hrs) with $50 \mu \mathrm{M}$ carmofur imaging with the brightlight (C), with the fluorescent light (D). Brightlight imaging of control live cells (blue arrows) and death cells (black arrows) are shown. Whereas a large number of apoptotic cells stained with Annexin-V-Alexa-488 (white arrows) were observed under fluorescent imaging when treated with carmofur, very little to no staining was seen in control untreated cells (B). 
a tumor promoter sphingosine-1-phosphate (Sph-1P), by sphingosine kinase 1 (SPHK1) or 2 (SPHK2) (Figure 7) [22]. Sph-1P stimulates glioblastoma cell invasiveness in vitro via the up-regulation of the urokinase plasminogen activator, its receptor, and proinvasive molecule CCN1 $[24,25]$. Ceramide has been shown to induce apoptosis in cells that have undergone radio- and chemotherpay $[18,22,23,26]$. The mechanism of action of ceramide appears to relate to the release of cytochrome c leading to the activation of caspase- 9 and caspase-3 [17]. ASAH1 is associated with tumor progression and invasiveness especially in melanoma, colon, and prostate cancers $[11,12,27]$. In particular, the treatment of the adult glioblastoma U87MG cell line with OE sensitizes these cells to radiation [16]. Among cell lines being studied, our Western blot data revealed the highest expression level of ASAH1 in CHLA200 cells (Figure 1). CHLA200 was generated at autopsy from a recurrent tumor invading the hemisphere, brainstem, and cerebellum, which had been previously treated with vincristine and radiotherapy [14]. Despite the prior radiation and chemotherapy, CHLA200 tumors still recurred in the patient that the cell line was derived from, which suggests this tumor is both radio- and chemoresistant $[13,14]$. Consistent with this finding, other investigators reported: 1) that over-expressed ASAH1 in prostate cells led to larger tumor volumes that are more resistant to chemotherapy; 2) when ASAH1 is suppressed, cells become more sensitive to chemotherapy; and 3)

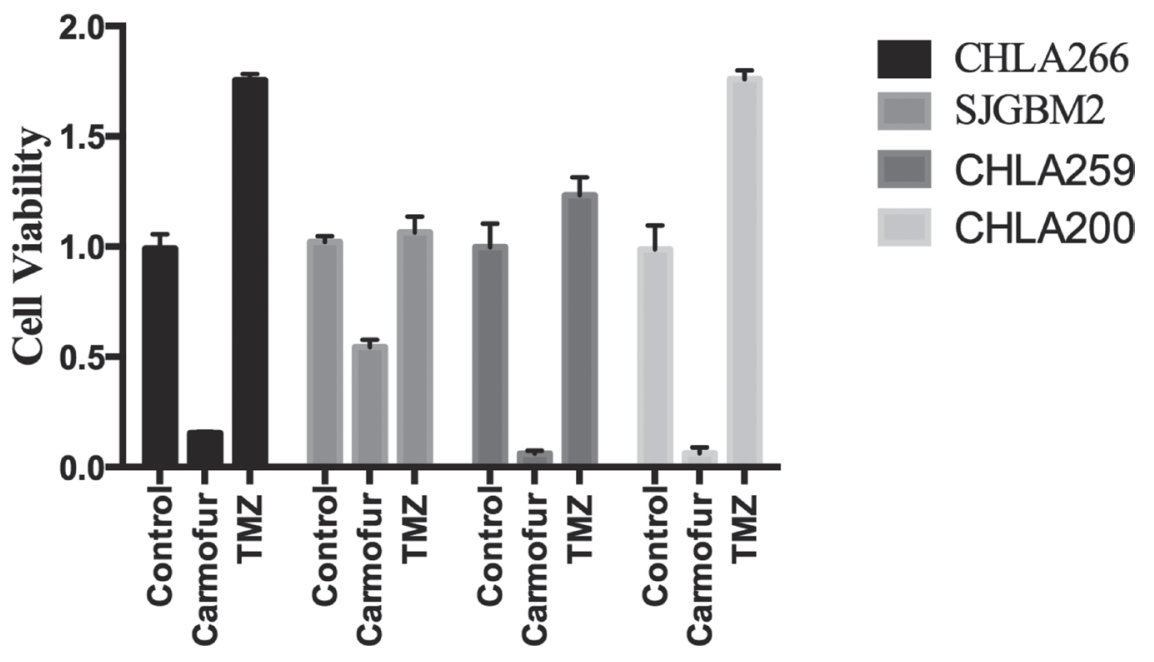

Figure 4: Pediatric brain tumors were more sensitive to carmofur than temozolomide. Cell survival studies using MTT assays of various pediatric brain tumors are shown for control cells vs cells treated with $50 \mu \mathrm{M}$ of carmofur and $100 \mu \mathrm{M}$ of TMZ. Results are expressed as means and \pm s.e.m $(N=3)$.

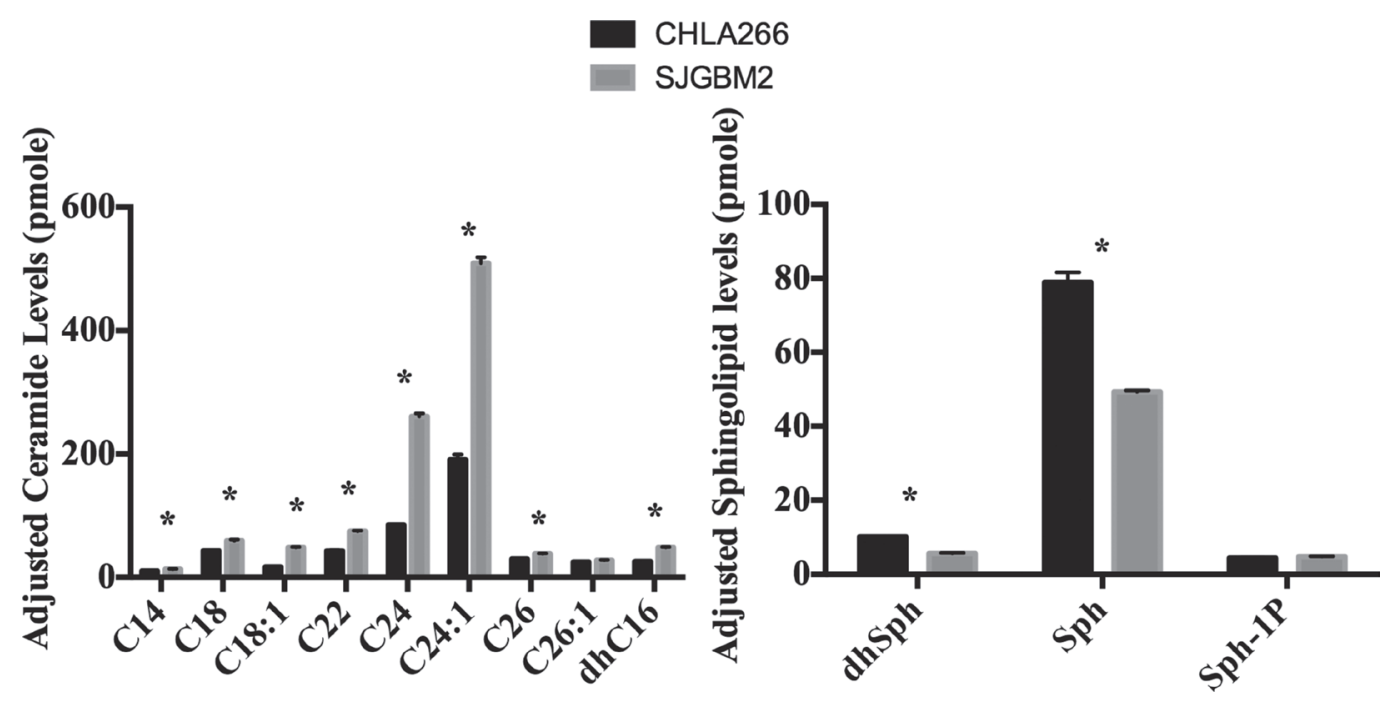

Figure 5: A high level of ASAH1 is associated with a lower level of its substrates and a higher level of its endproducts, ceramides and sphingosines, respectively. Cell pellets were prepared and lipids were extracted for mass spectrometry as described in Materials and Methods. Intracellular ceramide and sphingolipid levels are from CHLA266 (black bars) and SJGBM2 (gray bars) cells. These levels were adjusted for equal loading based on the phosphate level. Results shown are mean \pm SD of three replicates. $* P<0.05$. 
the treatment with B13, an ASAH1 inhibitor, sensitizes these cells to radiation $[11,28]$. We speculate that the high expression level of ASAH1, that was either induced by radiation or naturally occurring in the subpopulation of cells, enables CHLA200 cells to survive the prior radio- and chemotherapy. Due to the ability of ASAH1 to metabolize ceramides into $\mathrm{Sph}$, we also found that cells containing a higher level of ASAH1 are also associated with a lower level of ceramides and a higher level of Sph. Not too unexpectedly is that the intracellular level of Sph-1P is not influenced by the level of ASAH1 as other researchers have been shown that Sph-1P can be secreted into the extracellular space allowing cells to maintain a steady level of intracellular Sph-1P [23-25, 29] (Figure 5). Given its important role in cancer formation, prior studies have suggested ASAH1 as a novel anti-cancer target in other non-central-nervous-system cancers [20]. To test the effectiveness of ASAH1 inhibitors at targeting pediatric brain tumors, we treated these pediatric brain tumor cell lines with known ASAH1 inhibitors, carmofur and OE $[10,16,30]$. Despite their multidrug resistance phenotype, CHLA200, SJGBM2, CHLA266, and CHLA200 cells remain highly sensitive to carmofur and OE [13, 14] (Figure 2 and Table 1). No clear correlation between $\mathrm{IC}_{50}$ values and the level of ASAH1 expression was observed. This could be a result of having 4 different unrelated cells lines. In addition to the difference in ASAH1 expression level, the difference in the condition that the drug will be presented with in each of these cell lines could also influence $\mathrm{IC}_{50}$ values. Cells treated with ASAH1 inhibitors are induced to undergo apoptosis due to the elevated level of ceramide (Figure 6) [18, 22]. As expected, we demonstrated that all of these cell lines underwent apoptosis when treated with carmofur as evidenced by the binding of the Annexin-V-Alexa-488 conjugate, which produced the fluorescent signal observed under fluorescent microscopy (Figure 3). For comparison, we evaluated the effectiveness of TMZ against these pediatric brain tumor

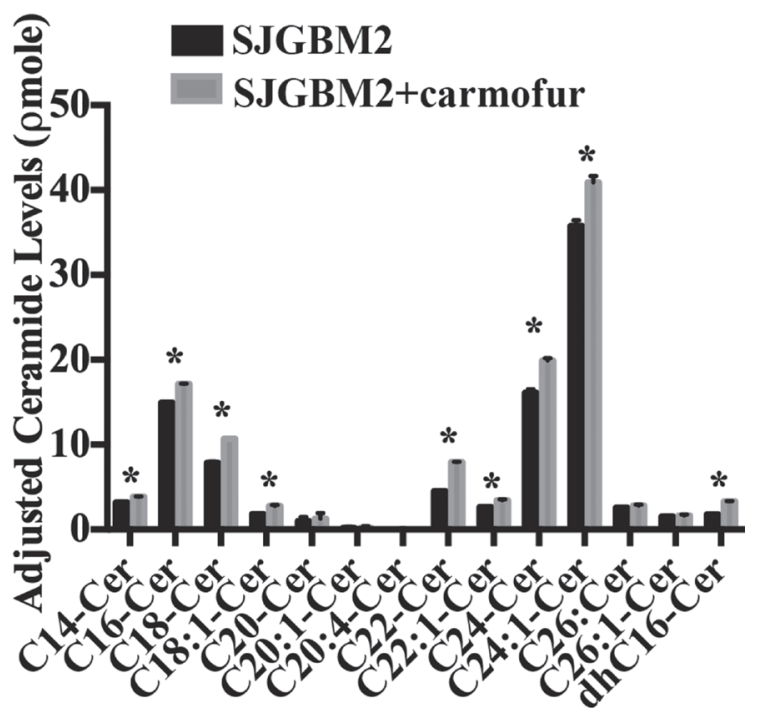

Figure 6: Treatment of SJGBM2 cells with carmofur resulted in intracellular accumulation of ceramides. Cell pellets were prepared and lipids were extracted for mass spectrometry as described in Materials and Methods. Intracellular ceramide and sphingolipid levels are from SJGBM2 cells (black bars) and SJGBM2 cells treated with $50 \mu \mathrm{M}$ carmofur (gray bars). These levels were adjusted for equal loading based on the phosphate level. Results shown are mean $\pm \mathrm{SD}$ of three replicates. $* P<0.05$.

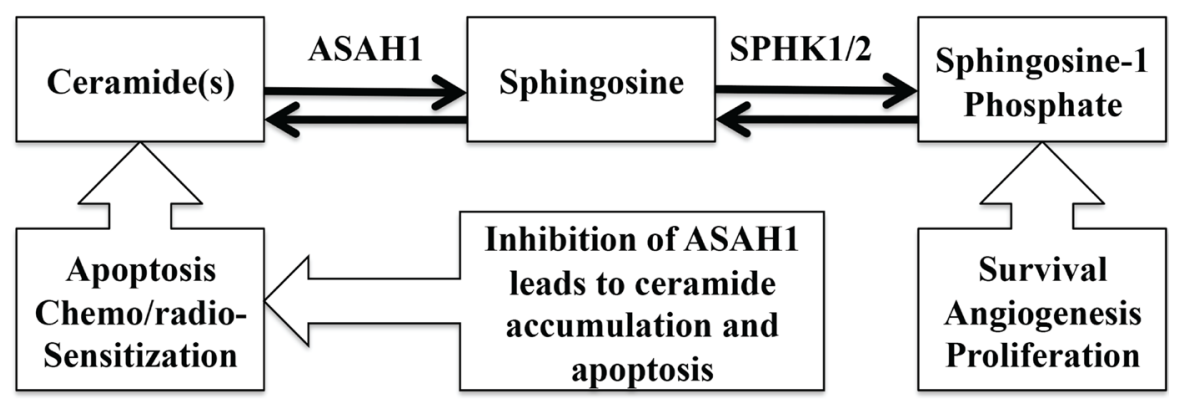

Figure 7: The schematic diagram of the metabolic ceramide pathway is shown. ASAH1 converts ceramide into sphingosine, which is subsequently metabolized to sphingosine-1-phosphate by SPHK1 or 2. Ceramide is a tumor suppressor, promoting apoptosis and chemo/radio-sensitization. Sphingosine-1-phosphate is a tumor promoter, enhancing survival, angiogenesis, and proliferation. 
cell lines. Not surprisingly, given their known multidrug resistance phenotype, TMZ was not effective at targeting any of the pediatric brain tumors tested (Figure 4). For unclear reason(s), TMZ actually enhanced the cell growth of CHLA200 and CHLA266 cell lines when treated over a period of 12 hours. A recent report by Stepanenko et al demonstrated that $\mathrm{TMZ}$ treatment of glioblastoma cells results in diverse responses that include enhanced proliferation and migration due to chromosomal instability induced by TMZ [31]. Further investigation is needed to determine if a similar mechanism of effect is playing a role here as well. These results suggest that carmofur is apt to be much more effective than TMZ and is a promising drug that should be further evaluated to treat multiple pediatric brain tumors. Carmofur has been used as a treatment for colorectal cancers since 1981 and has been shown to be able to cross the blood-brain barrier [10, 30].

\section{MATERIALS AND METHODS}

\section{Reagents and cells}

Mouse antibody against ASAH1 (612302) was purchased from BD Biosciences (San Jose, CA). Anti-actin, carmofur, temozolomide (TMZ), and N-oleoylethanolamine (OE), 3-(4,5-dimethylthiazol-2-yl)2,5-diphenyltetrazolium bromide (MTT) were purchased from Sigma Aldrich (St. Louis, MO). DMSO, used to dissolve carmofur, temozolomide, and OE, was purchased from Sigma Aldrich (St. Louis, MO). HRP-conjugated goat anti-mouse IgG was supplied by R\&D Systems, Inc. (Minneapolis, MN). SDS-PAGE and Western blotting materials and the Annexin V kit were obtained from Life Technologies, Inc. (Grand Island, NY).

\section{Cells}

Pediatric Anaplastic medulloblastoma (CHLA259), pediatric glioblastoma (SJGBM2 and CHLA200), and pediatric atypical teratoid rhabdoid tumors (CHLA266) were obtained from the Children's Oncology Group (COG) Cell Culture and Xenograft Repository [13-15]. SJGBM2 and CHLA200 are classified as glioblastoma, not otherwise specified (NOS), CHLA259 as medulloblastoma, NOS, according to the World Health Organization (WHO) 2016 classification of tumors of the central nervous system [32]. These cells were grown in Iscove's modified Dulbecco's medium supplemented with $20 \%$ fetal bovine serum, $4 \mathrm{mM}$ L-glutamine, and 1X ITS $(5 \mu \mathrm{g} / \mathrm{mL}$ insulin, $5 \mu \mathrm{g} / \mathrm{mL}$ transferrin, $5 \mathrm{ng} / \mathrm{mL}$ selenous acid).

\section{Western blot analysis and quantification}

Equal amounts $(15 \mu \mathrm{g})$ of protein from each of the tumor samples were loaded onto the $4,12 \%$ gel.
SDS-PAGE and Western blotting were performed using standard methods. Gel is blocked with $5 \%$ bovine serum albumin. A 1:500 dilution was used for primary antibody and 1:10,000 for secondary antibody. ImageJ software was used to quantify Western blot images.

\section{3-(4,5-dimethylthiazol-2-yl)-2,5- diphenyltetrazolium bromide (MTT) assays}

Cells were plated onto a 96-well plate at the density of $1 \times 10^{5}$ cells $/ \mathrm{ml}$. Media was exchanged to serum-free media after overnight incubation. Cells were treated with various drugs (OE, carmofur) dissolved in DMSO for 24 hours. MTT reagents were added after 24 hours of incubation, followed by acidic-isopropanol 4 hours later to dissolve formazan. All wells contained less than $0.2 \%$ of final concentration of DMSO. The absorbance values were recorded at wavelengths 570 and $630 \mathrm{~nm}$. $\mathrm{IC}_{50}$ 's were calculated with the GraphPad Prism software.

\section{Sphingolipid quantification}

Electrospray ionization tandem mass spectrometry (ESI/MS/MS) analysis of endogenous (phyto)sphingosine bases, sphingoid base-1-phosphates and (phyto)ceramide species were performed on a Thermo Fisher Quantum triple quadrupole mass spectrometer, operating in a Multiple Reaction Monitoring (MRM) positive ionization mode, using the modified version [33]. Briefly, biological materials were fortified with the internal standards (ISs: $\mathrm{C}_{17}$ base D-erythro-sphingosine (17CSph), $\mathrm{C}_{17}$ sphingosine1-phosphate (17CSph-1P), N-palmitoyl-D-erythro- $\mathrm{C}_{13}$ sphingosine (13C16-Cer) and heptadecanoyl-D-erythrosphingosine (C17-Cer) and C6-Phyto-ceramide), then extracted with ethyl acetate/iso-propanol/water (60/30/10 $\% \mathrm{v} / \mathrm{v}$ ) solvent system. After evaporation and reconstitution in $150 \mu \mathrm{l}$ of methanol, samples were injected on the HP1100/TSQ Quantum LC/MS system and gradient eluted from the BDS Hypersil C8, $150 \times 3.2 \mathrm{~mm}, 3 \mu \mathrm{m}$ particle size column, with $1.0 \mathrm{mM}$ methanolic ammonium formate $/ 2 \mathrm{mM}$ aqueous ammonium formate mobile phase system. Peaks corresponding to the target analytes and internal standards were collected and processed using the Xcalibur software system. Quantitative analysis was based on the calibration curves generated by spiking an artificial matrix with the known amounts of the target analyte synthetic standards and an equal amount of the internal standards (ISs). The target analyte/IS peak areas ratios were plotted against analyte concentration. The target analyte/IS peak area ratios from the samples were similarly normalized to their respective ISs and compared to the calibration curves, using a linear regression model. Introduction of the internal standards to the samples prior to extraction, yields results already "recovery corrected," therefore, no further data manipulation are necessary. 


\section{Fluorescent microscopy}

Cells were plated onto a 96-well plate at the density of $1 \times 10^{4} \mathrm{cells} / \mathrm{ml}$. Media was exchanged to serum-free media after overnight incubation. Cells were treated with various drugs for 12 hours then labeled with the AnnexinV-Alexa-488 conjugate according to the manufacturer's instructions. Imaging was recorded with a Zeiss Axiovert 200M inverted fluorescent microscope.

\section{CONCLUSIONS}

We demonstrated that medulloblastoma, pediatric glioblastoma, and atypical teratoid rhabdoid cell lines express significant levels of acid ceramidase, where levels are highest in the radioresistant tumors, suggesting that acid ceramidase may confer radioresistance. More importantly, we also showed that acid ceramidase inhibitors are highly effective at targeting these pediatric brain tumors with low $\mathrm{IC}_{50}$ values $(4.6,50 \mu \mathrm{M})$. This data suggests acid ceramidase could be used as a novel drug target for adjuvant pediatric brain tumor therapies. Of these acid ceramidase inhibitors, carmofur has seen clinical use in Japan since 1981 for colorectal cancers and is a promising drug to undergo further animal studies and subsequently a clinical trial for pediatric patients with brain tumors.

\section{Abbreviations}

ASAH1, acid ceramidase, ATRT, atypical teratoid rhabdoid tumors, DMSO, dimethyl sulfoxide, ESI/MS/ MS, electrospray ionization tandem mass spectrometry, GBM, glioblastoma, dhSph, dihydrosphingosine, $\mathrm{IC}_{50}$, half maximal inhibitory concentration, ISs, internal standards, MTT, 3-(4,5-dimethylthiazol-2-yl)-2,5diphenyltetrazolium bromide, $\mathrm{OE}, \mathrm{N}$-oleoylethanolamine, SDS-PAGE, sodium dodecyl sulfate polyacrylamide gel electrophoresis, Sph, sphingosine, Sph-1P, sphingosine-1phosphate, TMZ, temozolomide.

\section{ACKNOWLEDGMENTS}

We would like to thank the Children's Oncology Group (COG) Cell Culture and Xenograft Repository for providing the tumor samples used in this study. We also would like to thank Jan Schiebenes for helping with the editing, and the Department of Neurosurgery and Musella Foundation for their funding supports.

\section{CONFLICTS OF INTEREST}

The authors disclose no potential conflicts of interest.

\section{FUNDING}

Musella Foundation Grant, Department of Neurosurgery Larson Endowment Grant.

\section{REFERENCES}

1. Packer RJ, Gajjar A, Vezina G, Rorke-Adams L, Burger PC, Robertson PL, Bayer L, LaFond D, Donahue BR, Marymont MH, Muraszko K, Langston J, Sposto R. Phase III study of craniospinal radiation therapy followed by adjuvant chemotherapy for newly diagnosed averagerisk medulloblastoma. Journal of clinical oncology. 2006; 24:4202-4208.

2. Schrey D, Carceller Lechon F, Malietzis G, Moreno L, Dufour C, Chi S, Lafay-Cousin L, von Hoff K, Athanasiou T, Marshall LV, Zacharoulis S. Multimodal therapy in children and adolescents with newly diagnosed atypical teratoid rhabdoid tumor: individual pooled data analysis and review of the literature. Journal of neurooncology. 2016; 126:81-90.

3. Mallick S, Gandhi AK, Joshi NP, Kumar A, Puri T, Sharma DN, Haresh KP, Gupta S, Julka PK, Rath GK, Sarkar C. Outcomes of pediatric glioblastoma treated with adjuvant chemoradiation with temozolomide and correlation with prognostic factors. Indian journal of medical and paediatric oncology. 2015; 36:99-104.

4. Mallick S, Gandhi AK, Rath GK. Therapeutic approach beyond conventional temozolomide for newly diagnosed glioblastoma: Review of the present evidence and future direction. Indian journal of medical and paediatric oncology. 2015; 36:229-237.

5. Packer RJ, Goldwein J, Nicholson HS, Vezina LG, Allen JC, Ris MD, Muraszko K, Rorke LB, Wara WM, Cohen BH, Boyett JM. Treatment of children with medulloblastomas with reduced-dose craniospinal radiation therapy and adjuvant chemotherapy: A Children's Cancer Group Study. Journal of clinical oncology. 1999; 17:2127-2136.

6. Massimino M, Biassoni V, Gandola L, Garre ML, Gatta G, Giangaspero F, Poggi G, Rutkowski S. Childhood medulloblastoma. Critical reviews in oncology/hematology. 2016; 105:35-51.

7. Packer RJ. Chemotherapy for medulloblastoma/primitive neuroectodermal tumors of the posterior fossa. Annals of neurology. 1990; 28:823-828.

8. Palmer SL, Reddick WE, Gajjar A. Understanding the cognitive impact on children who are treated for medulloblastoma. Journal of pediatric psychology. 2007; 32:1040-1049.

9. Palmer SL. Neurodevelopmental impact on children treated for medulloblastoma: a review and proposed conceptual model. Developmental disabilities research reviews. 2008; 14:203-210. 
10. Realini N, Solorzano C, Pagliuca C, Pizzirani D, Armirotti A, Luciani R, Costi MP, Bandiera T, Piomelli D. Discovery of highly potent acid ceramidase inhibitors with in vitro tumor chemosensitizing activity. Scientific reports. 2013; 3:1035.

11. Saad AF, Meacham WD, Bai A, Anelli V, Elojeimy S, Mahdy AE, Turner LS, Cheng J, Bielawska A, Bielawski J, Keane TE, Obeid LM, Hannun YA, et al. The functional effects of acid ceramidase overexpression in prostate cancer progression and resistance to chemotherapy. Cancer biology \& therapy. 2007; 6:1455-1460.

12. Seelan RS, Qian C, Yokomizo A, Bostwick DG, Smith DI, Liu W. Human acid ceramidase is overexpressed but not mutated in prostate cancer. Genes, chromosomes \& cancer. 2000; 29:137-146.

13. Kang MH, Smith MA, Morton CL, Keshelava N, Houghton PJ, Reynolds CP. National Cancer Institute pediatric preclinical testing program: model description for in vitro cytotoxicity testing. Pediatric blood \& cancer. 2011; 56:239-249.

14. Xu J, Erdreich-Epstein A, Gonzalez-Gomez I, Melendez EY, Smbatyan G, Moats RA, Rosol M, Biegel JA, Reynolds CP. Novel cell lines established from pediatric brain tumors. Journal of neuro-oncology. 2012; 107:269-280.

15. Houghton PJ, Cheshire PJ, Hallman JD, 2nd, Lutz L, Friedman HS, Danks MK, Houghton JA. Efficacy of topoisomerase I inhibitors, topotecan and irinotecan, administered at low dose levels in protracted schedules to mice bearing xenografts of human tumors. Cancer chemotherapy and pharmacology. 1995; 36:393-403.

16. Hara S, Nakashima S, Kiyono T, Sawada M, Yoshimura S, Iwama T, Banno Y, Shinoda J, Sakai N. p53-Independent ceramide formation in human glioma cells during gammaradiation-induced apoptosis. Cell death and differentiation. 2004; 11:853-861.

17. Sawada M, Nakashima S, Banno Y, Yamakawa H, Hayashi K, Takenaka K, Nishimura Y, Sakai N, Nozawa Y. Ordering of ceramide formation, caspase activation, and $\mathrm{Bax} / \mathrm{Bcl}-2$ expression during etoposide-induced apoptosis in C6 glioma cells. Cell death and differentiation. 2000; 7:761-772.

18. Pettus BJ, Chalfant CE, Hannun YA. Ceramide in apoptosis: an overview and current perspectives. Biochimica et biophysica acta. 2002; 1585:114-125.

19. Segui B, Andrieu-Abadie N, Jaffrezou JP, Benoist H, Levade T. Sphingolipids as modulators of cancer cell death: potential therapeutic targets. Biochimica et biophysica acta. 2006; 1758:2104-2120.

20. Zeidan YH, Jenkins RW, Korman JB, Liu X, Obeid LM, Norris JS, Hannun YA. Molecular targeting of acid ceramidase: implications to cancer therapy. Current drug targets. 2008; 9:653-661.

21. Stupp R, Mason WP, van den Bent MJ, Weller M, Fisher B, Taphoorn MJ, Belanger K, Brandes AA, Marosi C, Bogdahn U, Curschmann J, Janzer RC, Ludwin SK, et al. Radiotherapy plus concomitant and adjuvant temozolomide for glioblastoma. The New England journal of medicine. 2005; 352:987-996.

22. Ogretmen B, Hannun YA. Biologically active sphingolipids in cancer pathogenesis and treatment. Nature reviews Cancer. 2004; 4:604-616.

23. Taha TA, Mullen TD, Obeid LM. A house divided: ceramide, sphingosine, and sphingosine-1-phosphate in programmed cell death. Biochimica et biophysica acta. 2006; 1758:2027-2036.

24. Young N, Van Brocklyn JR. Roles of sphingosine-1-phosphate (S1P) receptors in malignant behavior of glioma cells. Differential effects of S1P2 on cell migration and invasiveness. Experimental cell research. 2007; 313:1615-1627.

25. Young N, Pearl DK, Van Brocklyn JR. Sphingosine-1phosphate regulates glioblastoma cell invasiveness through the urokinase plasminogen activator system and CCN1/ Cyr61. Molecular cancer research. 2009; 7:23-32.

26. Bieberich E. Ceramide signaling in cancer and stem cells. Future lipidology. 2008; 3:273-300.

27. Pitson SM, Moretti PA, Zebol JR, Lynn HE, Xia P, Vadas MA, Wattenberg BW. Activation of sphingosine kinase 1 by ERK1/2-mediated phosphorylation. The EMBO journal. 2003; 22:5491-5500.

28. Samsel L, Zaidel G, Drumgoole HM, Jelovac D, Drachenberg C, Rhee JG, Brodie AM, Bielawska A, Smyth MJ. The ceramide analog, B13, induces apoptosis in prostate cancer cell lines and inhibits tumor growth in prostate cancer xenografts. The Prostate. 2004; 58:382-393.

29. Cheng JC, Bai A, Beckham TH, Marrison ST, Yount CL, Young $\mathrm{K}, \mathrm{Lu} \mathrm{P}$, Bartlett AM, Wu BX, Keane BJ, Armeson KE, Marshall DT, Keane TE, et al. Radiationinduced acid ceramidase confers prostate cancer resistance and tumor relapse. The Journal of clinical investigation. 2013; 123:4344-4358.

30. Pizzirani D, Pagliuca C, Realini N, Branduardi D, Bottegoni G, Mor M, Bertozzi F, Scarpelli R, Piomelli D, Bandiera T. Discovery of a new class of highly potent inhibitors of acid ceramidase: synthesis and structureactivity relationship (SAR). Journal of medicinal chemistry. 2013; 56:3518-3530.

31. Stepanenko AA, Andreieva SV, Korets KV, Mykytenko DO, Baklaushev VP, Huleyuk NL, Kovalova OA, Kotsarenko KV, Chekhonin VP, Vassetzky YS, Avdieiev SS, Dmitrenko VV. Temozolomide promotes genomic and phenotypic changes in glioblastoma cells. Cancer cell international. 2016; 16:36.

32. Louis DN, Perry A, Reifenberger G, von Deimling A, Figarella-Branger D, Cavenee WK, Ohgaki H, Wiestler OD, Kleihues P, Ellison DW. The 2016 World Health Organization Classification of Tumors of the Central Nervous System: a summary. Acta neuropathologica. 2016; 131:803-820.

33. Bielawski J, Szulc ZM, Hannun YA, Bielawska A. Simultaneous quantitative analysis of bioactive sphingolipids by high-performance liquid chromatographytandem mass spectrometry. Methods. 2006; 39:82-91. 